\title{
Synthesis of a novel environmental friendly plasticizer based on tung oil fatty acid for poly (vinyl chloride) blends
}

\author{
Hanqing Tong', Jinping $\mathrm{Hai}^{2 *}$ \\ ${ }^{1}$ College of Chemical Engineering, Guangdong University of Petrochemical Technology, Maoming, GuangDong, 525000, \\ P. R. China \\ ${ }^{2}$ College of Environmental and Biological Engineering, Guangdong University of Petrochemical Technology, Maoming, \\ Guangdong, 525000, P. R. China \\ "Corresponding author: e-mail: haijinping@gdupt.edu.cn
}

\begin{abstract}
A novel environmental friendly plasticizer (TPE) derived from tung oil fatty acid with long fatty acid chain and high degree of branching was synthesized. Chemical structure of the obtained TPE was characterized with Fourier transform infrared spectroscopy (FT-IR) and ${ }^{1} \mathrm{H}$ NMR. TPE was used to prepare plasticized PVC blends as main plasticizer. Thermal stability, mechanical properties and migration resistance of poly (vinyl chloride) plasticized with TPE were investigated. The results showed that torque data of plasticized PVC blends reached $12.4 \mathrm{~N} \cdot \mathrm{m}$ when the mass of the TPE was 50 wt.\%. TPE improved the thermal stability of PVC blends obviously than dioctyl phthalate (DOP). The leaching tests showed that PVC plasticized with TPE were with higher migration resistance than that of DOP. The excellent thermal stability and high migration resistance of PVC blends showed high application value for TPE.
\end{abstract}

Keywords: Synthesis, plasticizer, migration resistance, poly (vinyl chloride).

\section{INTRODUCTION}

Poly (vinyl chloride) (PVC) is used in a wide range of products as the third most widely produced plastic in the world ${ }^{1}$. PVC by itself is very rigid, brittle, and inflexible and cannot be suitable for processing and utilization. Thus, PVC products are often cooperated with a large amount of plasticizers. Plasticizers could modify the thermal and mechanical properties of PVC. The most commonly used plasticizers for PVC are phthalates, especially, the dioctyl phthalate (DOP). But phthalate esters are low molar mass compounds, which are easily released from PVC products. Phthalate esters can easily migrate from PVC products to foods and blood when the plasticized PVC products were used for food packing materials and blood transfusion hose $\mathrm{e}^{2-4}$. The loss of plasticizers could cause changes in thermal and mechanical properties of PVC products as well as possible toxic and biological effects when the plasticizers are transferred to human ${ }^{5-7}$.

To solve these problems, many researches have explored the new plasticizers such as epoxidized cardanol glycidyl ether ${ }^{8}$, epoxidized cardanol diethyl phosphate ${ }^{9}$, tung-oil-based triglycidyl ester ${ }^{10}$, epoxidized glycidyl ester of ricinoleic acetic ester ${ }^{11}$, hydrogenated cardanol glycidyl ether acetic ester containing phosphaphenanthrene group ${ }^{12}$, cardanol based internal plasticizer ${ }^{13}$, chlorinated phosphate ester based on castor oil ${ }^{14}$, epoxidized jatropha oil $^{15}$, epoxidized linseed oil ${ }^{16}$, palm oil based polyester plasticizer $^{17}$, and epoxidized soybean oil (ESO) ${ }^{18,19}$. Cardanol based internal plasticizer can improve the flexibility of PVC materials and there is no plasticizer migration ${ }^{13}$. The internal plasticizing strategy using biomass resources is meaningful and plays a guiding role for the late-development area. Chlorinated phosphate ester based on castor oil containing rich flame retardants(chlorine and phosphorus) improved the thermal stability and flame retardancy of PVC materials as a functional plasticizer, which provided a new ideas for further application of functional vegetable oil ${ }^{14}$.
In the present paper, we have made an attempt to develop novel environment friendly plasticizers(TPE) based on vegetable oil fatty acid. The chemical structure of synthesized plasticizers is similar to vegetable oil but with higher degree of branching than vegetable oil. Chemical structure of the obtained plasticizer was characterized with FT-IR and ${ }^{1} \mathrm{H}$ NMR. The thermal stability, plasticizing performance, solvent resistance of the plasticized PVC blends with TPE were investigated and compared with DOP.

\section{EXPERIMENTAL}

\section{Material}

Pentaerythritol, tung oleic acid, tetrabutyl titanate, dioctyl phthalate, calcium stearate and zinc stearate, olive oil, ethanol, acetic acid and petroleum ether were provided by Nanjing Chemical Reagent Co., Ltd. (China). All of the chemical reagents were analytically pure and used without further processing. Polyvinyl chloride (PVC) was supplied by Hanwha (South Korea) with K value 65.0 and degree of polymerization $1300 \pm 100$.

\section{Synthesis of tung oleic acid pentaerythritol ester(TPE)}

Pentaerythritol $(27.2 \mathrm{~g}, 0.2 \mathrm{~mol})$, tung oleic acid $(278.0 \mathrm{~g}, 1.0 \mathrm{~mol})$ and tetrabutyl titanate $(2.78 \mathrm{~g}, 0.01 \mathrm{~mol})$ was mixed in a four-necked round-bottom flask which was equipped with a mechanical stirrer, condenser pipe, thermometer and constant pressure funnel. The mixture was stirred at $220^{\circ} \mathrm{C}$ for $4 \mathrm{~h}$ to finish esterification. Then the reaction mixture was washed 3 times with distilled water and removed the water with a rotary evaporator to obtain the product. The synthesis route of TPE was showed in Figure 1.

\section{Preparation of PVC blends}

PVC blends were prepared in a Haake Reomix 600p (Haake Instrument Crop., Germany) with two co-rotors. The composition was given in Table 1. The processing 


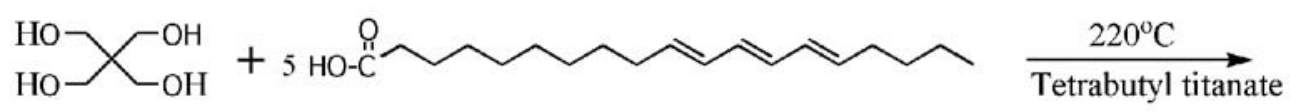

Pentaerythritol Tung oil fatty acid



Tung oleic acid pentaerythritol ester(TPE)

Figure 1. Synthesis of TPE

Table 1. Composition of PVC blends

\begin{tabular}{|c|c|c|c|c|}
\hline Sample & $\mathrm{a}$ & $\mathrm{b}$ & $\mathrm{c}$ & $\mathrm{d}$ \\
\hline $\mathrm{PVC} / \mathrm{g}$ & 100 & 100 & 100 & 100 \\
\hline $\mathrm{DOP} / \mathrm{g}$ & 50 & 0 & 0 & 0 \\
\hline $\mathrm{TPE} / \mathrm{g}$ & 0 & 30 & 40 & 50 \\
\hline $\begin{array}{c}\text { Calcium } \\
\text { stearate/g }\end{array}$ & 1 & 1 & 1 & 1 \\
\hline Zinc stearate/g & 1 & 1 & 1 & 1 \\
\hline
\end{tabular}

time was $5 \mathrm{~min}$ at $45 \mathrm{rpm}$. The mixture temperature was $160^{\circ} \mathrm{C}$. Then the dumbbell plasticized PVC blends were prepared in Haake Minijet Micro injection molding machine (Haake Instrument Crop., Germany) according GB/T 17037.1-1997 (China).

Iodine value. Iodine value of TPE was investigated according to the National standard of China (GB/T 1676-2008).

Acid value. Acid value of TPE was investigated according to the National standard of China (GB/T 1668-2008).

Saponification value. Saponification value of TPE was investigated according to the National standard of China (GB/T 1665-2008).

Viscosity. Viscosity of TPE was detected using a Brookfield Viscometer at $25^{\circ} \mathrm{C}$.

FT-IR. FT-IR spectra of TPE was detected using the liquid membrane method and recorded on a Nicolet iS10 FT-IR (Nicolet Instrument Crop., USA) Fourier transformed infrared spectrometer. TPE was dripped in two pieces of gasket and gently clamped for determination. The PVC samples were pre-dried prior to measurement to avoid the influence of moisture vibration spectra. The spectra were acquired in the range of 4000 to $500 \mathrm{~cm}^{-1}$ at a resolution of $4 \mathrm{~cm}^{-1}$.

${ }^{1} \mathbf{H}$ NMR. ${ }^{1} \mathrm{H}$ NMR spectra of the obtained TPE was recorded by using an AV-300 NMR spectrometer (Bruker, Germany) at a frequency of $400 \mathrm{MHz}$ with tetrametnylsilane as an internal standard.

Torque evaluation. PVC blends were prepared in a Haake Reomix 600p with two co-rotors. The composition was given in Table 1 . The processing time was $5 \mathrm{~min}$ at $45 \mathrm{rpm}$. The applied torque was monitored during this period. The mixture temperature was $160^{\circ} \mathrm{C}$.

Thermogravimetric Analysis (TGA). TGA was carried out in a TG209F1 TG thermal analysis instruments (Netzsch Instrument Crop., German) in $\mathrm{N}_{2}$ atmosphere $\left(50 \mathrm{ml} \cdot \mathrm{min}^{-1}\right)$ at a heating rate of $10^{\circ} \mathrm{C} \cdot \mathrm{min}^{-1}$. The samples was measured in a platinum pan with a mass of about $5 \mathrm{mg}$ and scanned from $40^{\circ} \mathrm{C}$ to $600^{\circ} \mathrm{C}$.

Dynamic mechanical analysis (DMA). The dynamic mechanical analysis was performed via a DMTA Q800 (TA Instruments, US) with gas cooling accessory to observe the $\alpha$-transitions of the PVC blends under investigation. Rectangular samples of geometry $80(\mathrm{~L}) \times 10(\mathrm{~W}) \times 4(\mathrm{~T})$ $\mathrm{mm}^{3}$. The oscillatory frequency of the dynamic test was $1 \mathrm{~Hz}$. The temperature was raised at a rate of $3^{\circ} \mathrm{C} / \mathrm{min}$ in the range of $-80^{\circ} \mathrm{C}-100^{\circ} \mathrm{C}$.

SEM. The surface and cross section of PVC blends were investigated with a Hitachi 3400-1 (Hitachi, Japan) scanning electron microscope instrument, operated at $12 \mathrm{kv}$. The fracture of all surfaces was sputtered with gold to avoid electrostatic charging during examination.

Migration stability tests. Leaching tests were based on ASTMD1239-98. The test conditions were restricted at a temperature of $23 \pm 2{ }^{\circ} \mathrm{C}$ and $50 \pm 5 \%$ relative humidity. The PVC specimens were immersed in five different solvents (distill water, olive oil, $10 \%$ (v/v) ethanol, $30 \%$ $(\mathrm{w} / \mathrm{v})$ acetic acid and petroleum ether ). Samples were weight and kept in $200 \mathrm{~mL}$ of each solvent. After $24 \mathrm{~h}$, the solvent extracted PVC specimens were rinsed and then wiped up. Afterward, all of the PVC specimens were dried under the test conditions in oven at $30^{\circ} \mathrm{C}$ for $24 \mathrm{~h}$ and reweighed. The extraction loss was calculated according to the equation 1 .

Equation 1: Weight loss $\left.=\left[\left(\mathrm{W}_{1}-\mathrm{W}_{2}\right) / \mathrm{W}_{1}\right)\right] \times 100$, where $\mathrm{W}_{1}=$ initial weight of test specimen, and $\mathrm{W}_{2}=$ final weight of test PVC specimens ${ }^{\mathbf{2 0}, \mathbf{2 1}, \mathbf{2 2}}$.

Tensile tests. Tensile modulus, tensile strength, and elongation at break were determined according GB/T 1040.1-2006 (China) under ambient conditions, using E43.104 Universal Testing Machine (MTS Instrument Crop., China). The reported values were the average of 6 samples.

\section{RESULTS AND DISCUSSION}

\section{Physio-chemical properties of TPE}

Physio-chemical properties of TPE were investigated according to the National standard of China. The obtained TPE presented yellow sticky liquid at $25^{\circ} \mathrm{C}$. Viscosity of TPE was detected using a Brookfield Viscometer at $25^{\circ} \mathrm{C}$, the value was 0.9 Pas. Iodine value, acid value and saponification value of TPE was $182,6 \mathrm{mgKOH} / \mathrm{g}$ and 193, respectively.

\section{FT-IR}

The FT-IR spectra of TPE was showed in Figure 2. The peaks at 2923 and $2853 \mathrm{~cm}^{-1}$ were attributed to the $-\mathrm{C}-\mathrm{H}$ stretching and $-\mathrm{CH}_{2}$ anti-symmetric stretching vibrations respectively. The weak peak at $3012 \mathrm{~cm}^{-1}$ was corresponded to $-\mathrm{CH}_{3}$ stretching vibrations . There is a significant absorption peak at around $1741 \mathrm{~cm}^{-1}$, which attributed to the $-\mathrm{C}=\mathrm{O}$ functionality present in 


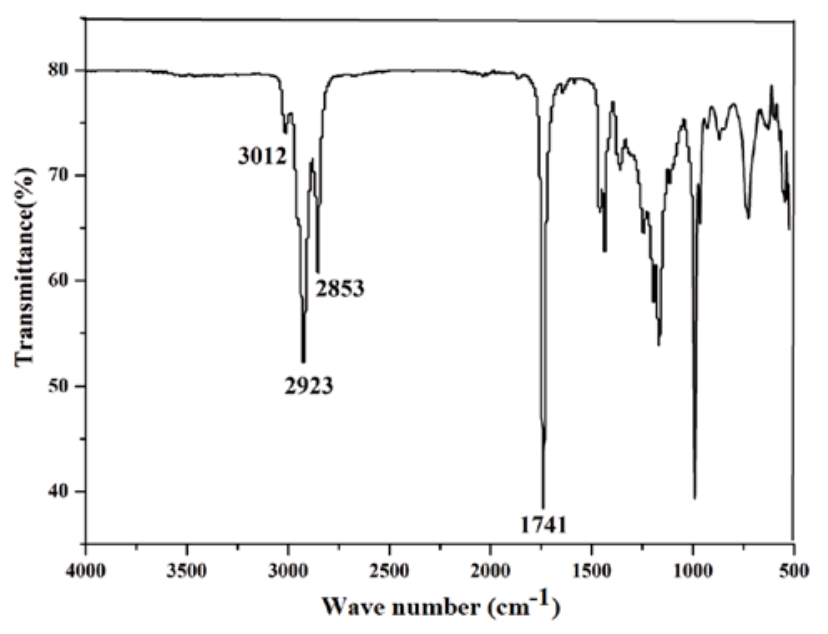

Figure 2. FT-IR of spectra of TPE

the ester groups. A small peak at around $1570-1600 \mathrm{~cm}^{-1}$ was attributed to conjugation. The peak at around 1000 $\mathrm{cm}^{-1}$ was attributed to $-\mathrm{C}-\mathrm{O}$ stretching vibration. The characteristic absorption peaks of -OH groups could not be found at around $3400-3500 \mathrm{~cm}^{-1},{ }^{23-25}$ which illustrated that the esterification reaction finished.

\section{${ }^{1}$ H NMR}

In order to further detect chemical structure of the obtained TPE, ${ }^{1} \mathrm{H}$ NMR of TPE was also obtained. The ${ }^{1} \mathrm{H}$ NMR spectra of TPE was showed in Figure 3. The protons of methyl groups on the unsaturated long fatty acid chains appeared at at $0.89 \mathrm{ppm}$. The strong peak at $1.25 \mathrm{ppm}$ was assigned to the protons of methylene groups. The protons of methylene groups connected the carbonyl groups appeared at $2.25 \mathrm{ppm}$, and the signals appeared at $4.13,4.26$ and 5.24 ppm were attributed to the methylene groups derived from pentaerythritol groups. The protons appeared at 1.59, 2.02, and $2.14 \mathrm{ppm}$ were corresponded to the other methylene groups. The protons of olefin groups appeared at the range of 5.33-6.17ppm $\mathrm{pm}^{23}$. There is not any absorption peak of impurity and absorption peak of free hydroxyl groups in the ${ }^{1} \mathrm{H}$ NMR of TPE, which illustrated that TPE was synthesized successfully.

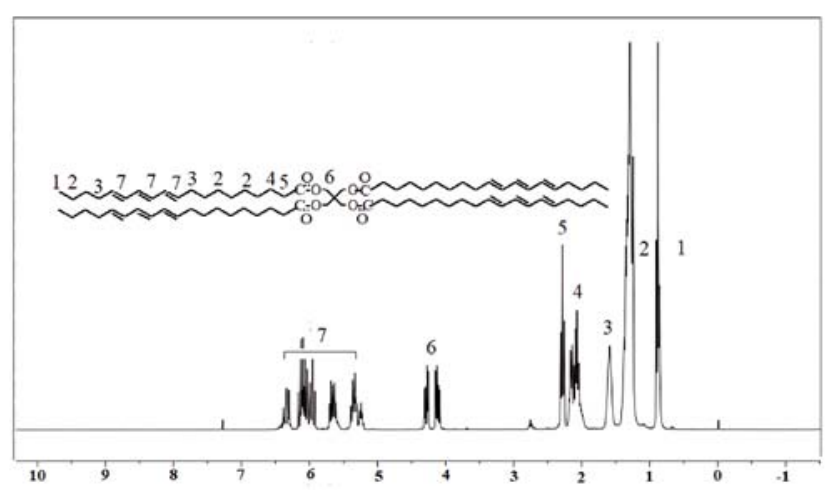

Figure 3. ${ }^{1} \mathrm{H}$ NMR spectra of TPE

\section{Melts blends torque evaluation}

The torque data was collected during mixing in the Haake chamber. Figure 4 presented the torque values relative to different plasticizer in PVC blends for the processing time of $4 \mathrm{~min}$. As seen from the Figure 4, the torque value of PVC plasticized with DOP and TPE was

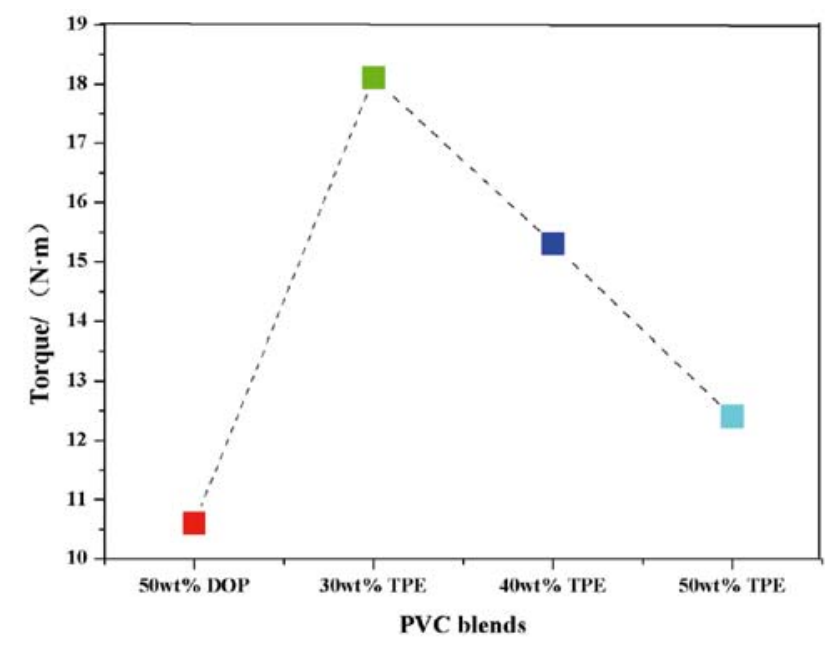

Figure 4. Torque data changes with the addition of TPE

10.6, 18.1, 15.3 and $12.4 \mathrm{~N} \cdot \mathrm{m}$, respectively. The torque values of TPE modified PVC was comparatively higher than the specimen containing 50 wt.\% DOP, which indicated the worse homogenization as compared with DOP incorporated specimen. Moreover, on increasing the content of TPE in the polymer matrix torque values are reduced due to the plasticization effect provided by the TPE. The torque data for sample d was $12.4 \mathrm{~N} \cdot \mathrm{m}$, which was closed to the torque data of sample a. Therefore, material homogenisation of sample a and sample d was similar.

\section{TGA}

Plasticizers usually change the thermal stability of plasticized PVC materials. In the study, thermal stability of plasticized PVC blends with DOP and TPE was characterized and compared. TGA and DTG analysis and illustrated in Figure 5 and Figure 6, respectively. The thermal performance data was showed in Table 2 . As seen from the TGA curves of PVC blends, the elimination of a large amount of $\mathrm{HCl}$ happened at around

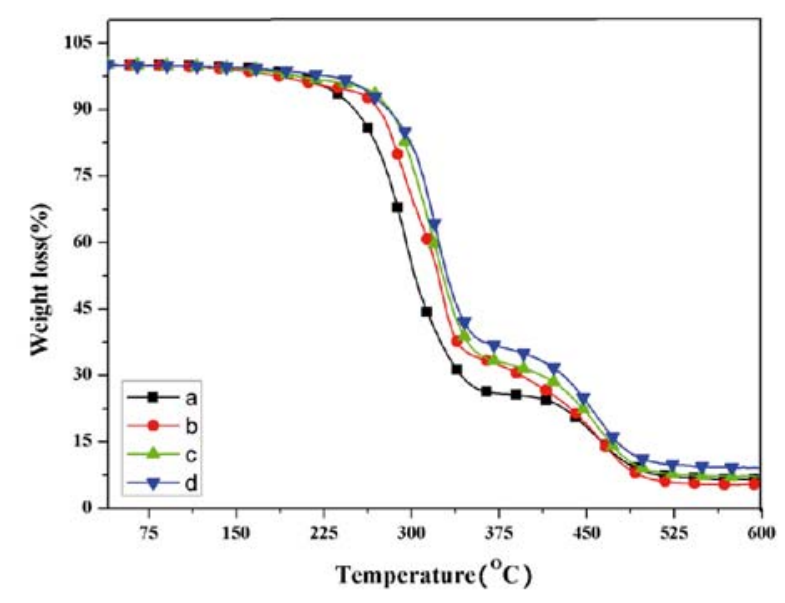

Figure 5. TGA curves of PVC blends

Table 2. TGA and DMA data of PVC blends

\begin{tabular}{|c|c|c|c|c|c|}
\hline $\begin{array}{c}\text { Sample } \\
\mathrm{s}\end{array}$ & $\mathrm{T}_{\mathrm{d}} /{ }^{\circ} \mathrm{C}$ & $\mathrm{T}_{10} /{ }^{\circ} \mathrm{C}$ & $\mathrm{T}_{50} /{ }^{\circ} \mathrm{C}$ & $\mathrm{T}_{\mathrm{g}} /{ }^{\circ} \mathrm{C}$ & $\begin{array}{c}\text { Char } \\
\text { residue } \\
/ \%\end{array}$ \\
\hline $\mathrm{a}$ & 251.6 & 215.4 & 318.0 & 38.2 & 7.16 \\
\hline $\mathrm{b}$ & 265.1 & 246.4 & 336.5 & 47.5 & 7.56 \\
\hline $\mathrm{c}$ & 287.3 & 250.7 & 351.8 & 52.1 & 9.94 \\
\hline $\mathrm{d}$ & 299.2 & 260.9 & 367.0 & 54.2 & 11.12 \\
\hline
\end{tabular}




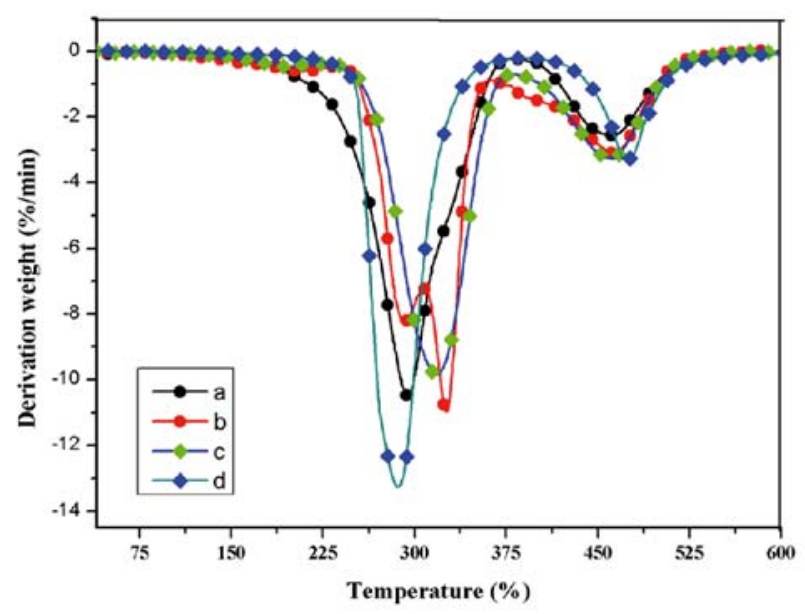

Figure 6. DTG curves of PVC blends

$200^{\circ} \mathrm{C}-400^{\circ} \mathrm{C}$, which is attributed to the first thermal degradation stage. The second stage at above $400^{\circ} \mathrm{C}$ is corresponded to cross linking containing $\mathrm{C}=\mathrm{C}$ bond. The process of thermal degradation of polyenes involves cyclization and splitting of chains ${ }^{26-28}$. The DTG curves of all PVC blends also presents two thermal degradation processes. The thermal performance data including decomposition temperature $\left(\mathrm{T}_{\mathrm{d}}\right)$, the mass loss of $10 \%$ $\left(\mathrm{T}_{10}\right)$, the mass loss of $50 \%\left(\mathrm{~T}_{50}\right)$ and char residue were summarized in the Table 2. $\mathrm{T}_{\mathrm{d}}, \mathrm{T}_{10}$ and $\mathrm{T}_{50}$ of all PVC plasticized with TPE were higher than DOP. $\mathrm{T}_{\mathrm{d}}, \mathrm{T}_{10}$ and $\mathrm{T}_{50}$ increased from $265.1,246.2$, and $336.5^{\circ} \mathrm{C}$ to 299.2 , 260.9 and $367.0^{\circ} \mathrm{C}$, respectively. The results indicated that TEP can improve the thermal stability than DOP. In addition, the amount char residue of sample $a, b, c$ and $d$ is $7.16,7.56,9.94$ and $11.12 \%$, which illustrated that TPE could increase char residue of PVC blends than DOP.

\section{DMA}

In order to investigated the compatibility and plasticizing efficiency of TEP. The dynamic mechanical property of PVC blends was measures by DMA, Figure 7 presented the DMA curves of all PVC blends, and the glass transition temperature $\left(\mathrm{T}_{\mathrm{g}}\right)$ values were shown in Table 2. It can be seen that all of the PVC blends showed only a $\tan \delta$ peak, which indicated that the DOP and TEP was compatible with PVC. $\mathrm{T}_{\mathrm{g}}$ for samples $\mathrm{a}, \mathrm{b}, \mathrm{c}$

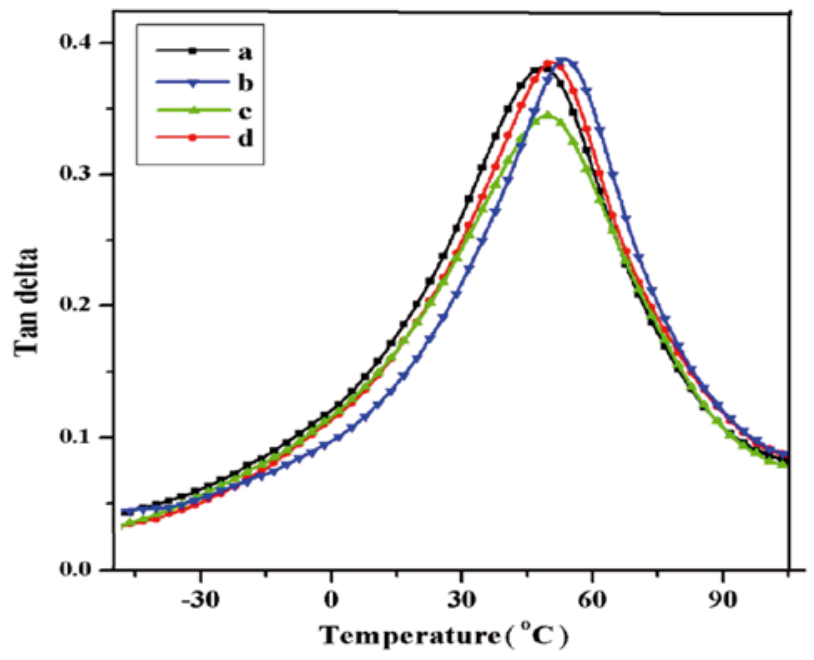

and $\mathrm{d}$ is $39.2,56.7,47.1$ and $43.5^{\circ} \mathrm{C}$, respectively. The lower Tg of PVC blends indicated that the compatibility of PVC and the plasticizer is better ${ }^{29-31}$.

\section{SEM}

The morphology of cross section of PVC blends was investigated with SEM, which was presented in Figure 8 (a1, b1, c1 and d1). The morphology of cross section of sample a showed smooth surface over the surfaced of PVC plasticized with DOP which could be seen in Figure 8 (a1). But sample b , c and d showed many wrinkles over the surfaced of PVC plasticized with TEP, which indicated that the compatibility of PVC and DOP is obviously better than TEP. However, wrinkles of PVC blends became little gradually with more TPE adding into the blends, which illustrated that PVC and TPE was well intersoluble.
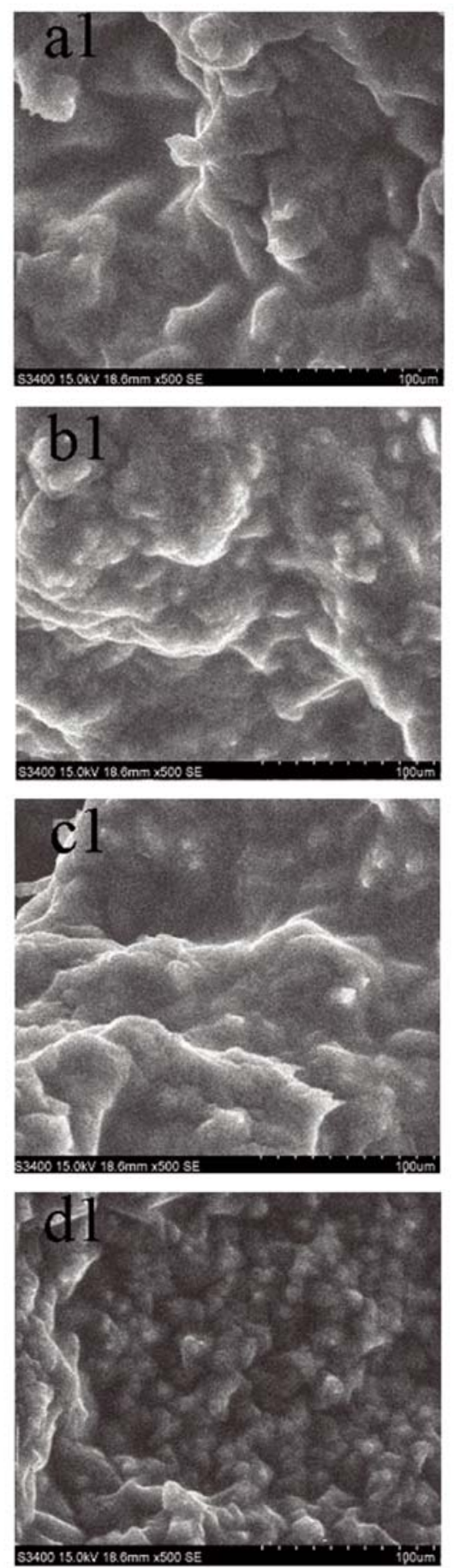

Figure 8. The morphology of cross section of PVC blends 


\section{Tensile tests}

The elongation at break, tensile strength and modulus of elasticity of PVC blends were presented in Table 3. Sample a showed a high elongation at break and low tensile strength compared with the other samples. Sample b presented the lowest elongation at break of $227.55 \%$ and the highest tensile strength of $36.99 \mathrm{Mpa}$. Tensile strength of sample d decreased from $36.99 \mathrm{MPa}$ to $18.93 \mathrm{MPa}$ with the more addition of TPE, which indicated that the TPE has similar plasticizing effect on PVC compared to DOP.

Table 3. Tensile properties of PVC blends

\begin{tabular}{|c|c|c|c|}
\hline Sample & $\begin{array}{c}\text { Modulus of } \\
\text { elasticity / Mpa }\end{array}$ & $\begin{array}{c}\text { Elongation at } \\
\text { break / \% }\end{array}$ & $\begin{array}{c}\text { Tensile } \\
\text { strength / } \\
\text { MPa }\end{array}$ \\
\hline a & 21.6 & 552.85 & 16.14 \\
\hline b & 105.16 & 227.55 & 36.99 \\
\hline c & 98.56 & 316.21 & 26.75 \\
\hline d & 52.9 & 478.27 & 18.93 \\
\hline
\end{tabular}

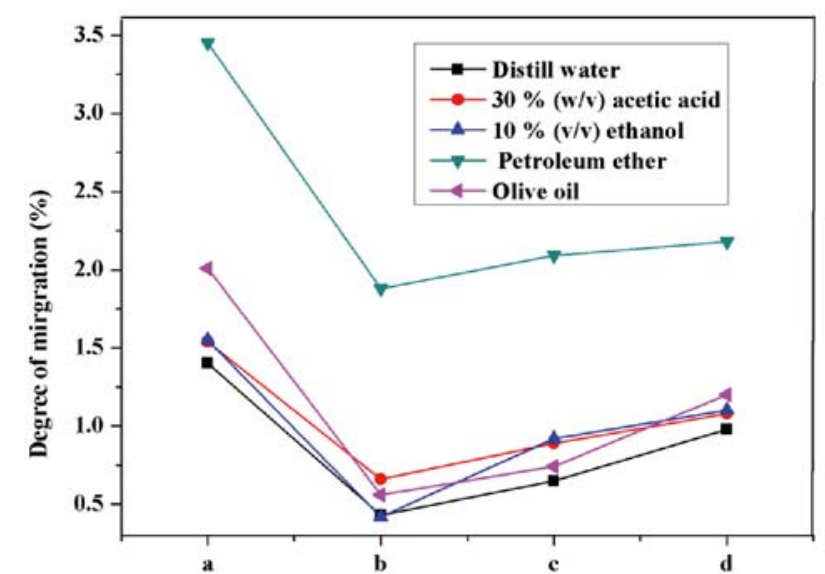

Figure 9. Migration stability of the PVC blends in five different solvents

The migration stability of the PVC blends samples was investigated by the leaching tests using five different solvents and the results were presented in Figure 9. Every value was the average of the values for five specimens of the same composition. As seen from the Figure 9, PVC blends samples showed different migration resistance when they were immersed in different solvents. It is impressive to observe that the migration of TPE were obviously lower into these five different solvents, it is indicated that TPE show higher migration resistance compared to DOP.

\section{FTIR}

The infrared absorption peak of carbonyl group of plasticizer will shift to a lower position when it was blended with $\mathrm{PVC}^{32-34}$. Figure 10 showed the FT-IR of spectra of PVC and Sample d. After the addition of TPE in to the PVC blend the related peak shifts from $1741 \mathrm{~cm}^{-1}$ (Figure 2) to $1735 \mathrm{~cm}^{-1}$ (Figure 10). The carbonyl group shifts more larger in the FT-IR spectrum indicates that the miscibility between PVC and plasiczer is better ${ }^{32,33}$. This suggests the possibility of the dipole interactions developed between the carbonyl group of TPE with chlorine atom of PVC present in the blend which in turn results in enhanced compatibility.

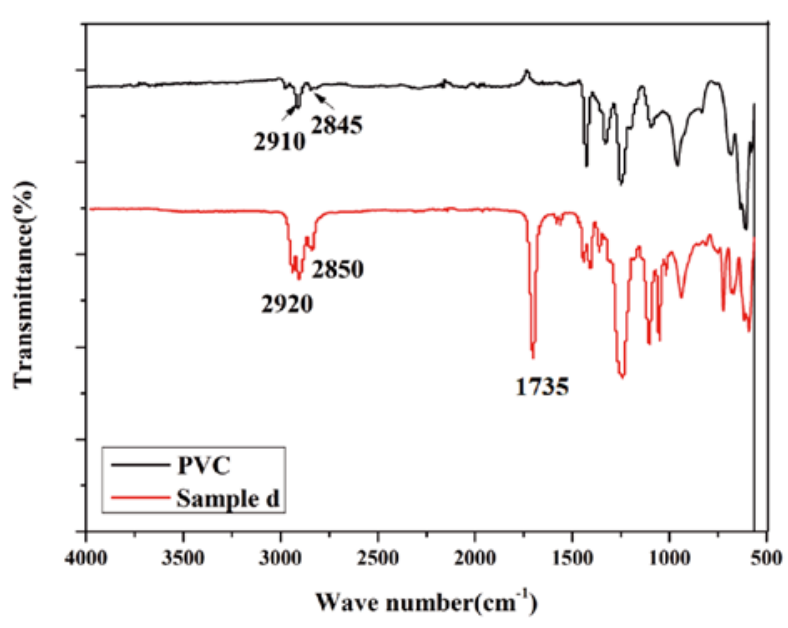

Figure 10. FT-IR of spectra of PVC and Sample d

\section{CONCLUSIONS}

In this study, we synthesis a novel environmental friendly plasticizer (TPE) with pentaerythritol and tung oleic acid. The obtained plasticizer with with long fatty acid chain and high degree of branching was used to prepare plasticized PVC blends. The properties of PVC plasticized with TPE and DOP were investigated and compared. The results indicated that TEP can improve the thermal stability than DOP. $\mathrm{T}_{\mathrm{d}}, \mathrm{T}_{10}$ and $\mathrm{T}_{50}$ reached $336.5^{\circ} \mathrm{C}$ to $299.2^{\circ} \mathrm{C}, 260.9^{\circ} \mathrm{C}$ and $367.0^{\circ} \mathrm{C}$, respectively. $\mathrm{T}_{\mathrm{g}}$ for samples $\mathrm{a}, \mathrm{b}, \mathrm{c}$ and $\mathrm{d}$ is $39.2,56.7,47.1$ and $43.5^{\circ} \mathrm{C}$. Tensile strength of sample d decreased from $36.99 \mathrm{MPa}$ to $18.93 \mathrm{MPa}$ with the more addition of TPE, which was closed to $16.14 \mathrm{MPa}$ of DOP, illustrating that the TPE has similar plasticizing effect on PVC compared with DOP. The leaching tests showed that PVC plasticized with TPE were with higher migration resistance than DOP. The excellent thermal stability and high migration resistance of PVC blends showed high application value for TPE.

\section{LITERATURE CITED}

1. Ang, D.T., Khong, Y.K. \& Gan, S.N. (2014). Palm oil-based compound as environmentally friendly plasticizer for poly(vinyl chloride). J. Vinyl Addit. Technol. 22 (1), 80-87. DOI $10.1002 / \mathrm{vnl} .21434$

2. Hsu, N.Y., Liu, Y.C., Lee, C.W. \& Su, H.J. (2017). Higher moisture content is associated with greater emissions of DEHP from PVC wallpaper. Environ. Res. 152, 1-6. DOI: 10.1016/j. envres.2016.09.027.

3. Pyeon, H.B., Park, J.E. \& Done, H.S.(2017). Non-phthalate plasticizer from camphor for flexible PVC with a wide range of available temperature. Polym. Test. 63. DOI 10.1016/j.polymertesting.2017.08.029.

4. Zheng, X. \& Gilbert, M. (2000). Impact strength of high density microcellular poly(vinyl chloride) foams. J. Vinyl Addit. Technol. 6(2), 93-99. DOI 10.1002/vnl.21408.

5. Shi, G.X., Cooper, D.G. \& Maric,M. (2011). Poly(E-caprolactone)-based 'green' plasticizers for poly(vinyl chloride). Polym. Degrad. Stabil. 96 (9), 1639-1647. DOI 10.1016/J. Polymdegradstab.2011.06.007.

6. Benaniba, M.T. \& Massardier-Nageotte, V.(2010). Evaluation effects of biobased plasticizer on the thermal, mechanical, dynamical mechanical properties, and permanence of plasticized PVC. J. Appl. Polym. Sci. 118 (6), 3499-3508. DOI 10.1002/app.32713.

7. Rahman, M. \& Bazel, C.S. (2004). The plasticizer market: an assessment of traditional plasticizers and research trends 
to meet new challenges. Prog. Polym. Sci. 29 (12), 1223-1248. DOI: https://doi.org/10.1016/j.progpolymsci.2004.10.001.

8. Jia, P., Zhang, M., Hu, L., Wang, R., Sun, C. \& Zhou, Y. (2017). Cardanol groups grafted on poly(vinyl chloride)-synthesis, performance and plasticization mechanism. Polymers, 9(11), 621. DOI: 10.3390/polym9110621.

9. Chen, J., Liu, Z., Li, X., Liu, P., Jiang, J. \& Nie, X. (2016) Thermal behavior of epoxidized cardanol diethyl phosphate as novel renewable plasticizer for poly(vinyl chloride). Polym. Degrad. Stabil. 126, 58-64. https://doi.org/10.1016/j.polymdegradstab.2016.01.018.

10. Chen, J.,Wang, Y., Huang, J., Li, K. \& Nie, X.(2018). Synthesis of tung-oil-based triglycidyl ester plasticizer and its effects on poly(vinyl chloride) soft films.ACS Sustainable Chem. Eng. 6(1), 642-651. DOI: 10.1021/acssuschemeng.7b02989.

11. Chen, J.,Wang, Y., Huang, J., Li, K., Nie, X. \& Jiang, J. (2017).Synthesis and properties of a novel environmental epoxidized glycidyl ester of ricinoleic acetic ester plasticizer for poly(vinyl chloride). Polymers. 9(12), 640. DOI: 10.3390/ polym9120640.

12. Chen, J., Nie, X. \& Jiang, J. (2018). Synthesis and application of a novel cardanol-based plasticizer as secondary or main plasticizer for poly(vinyl chloride). Polym. Int. 67(3), 269-275. DOI: https://doi.org/10.1002/pi.5503.

13. Jia, P., Hu, L., Shang, Q., Wang, R., Zhang, M. \& Zhou, Y. (2017). Self-Plasticization of PVC materials via chemical modification of mannich base of cardanol butyl ether. ACS Sustain. Chem Eng. 5(8), 6665-6673. DOI: 10.1021/acssuschemeng.7b00900.

14. Jia, P., Zhang, M., Liu, C., Hu, L., Feng, G., Bo, C. \& Zhou, Y. (2015). Effect of chlorinated phosphate ester based on castor oil on thermal degradation of poly (vinyl chloride) blends and its flame retardant mechanism as secondary plasticizer. RSC Adv. 2015, 5, 41169-41178. DOI 10.1039/C5RA05784A.

15. Chieng, B.W., Ibrahim, N.A., Then, Y.Y. \& Loo, Y.Y. (2017). Epoxidized jatropha oil as a sustainable plasticizer to poly(lactic acid). Polymers. 9, 204-214. DOI: 10.3390/polym9060204.

16. Fenollar, O., Garcia-sanoguera, D., Sanchez-Nacher, L., Lopez, J. \& Balart, R. (2013). Mechanical and thermal properties of polyvinyl chloride plasticized with natural fatty acid esters. Polymer-Plastics Technology and Engineering. 52, 751-767. https://doi.org/10.1080/03602559.2013.763352.

17. Jia,. P., Zhang, M., Hu, L. \& Zhou, Y. (2016).A novel biobased polyester plasticizer prepared from palm oil and its plasticizing effect on poly (vinyl chloride). Pol. J. Chem. Technol. 18(1), 9-14. DOI: https://doi.org/10.1515/pjct-2016-0002.

18. Lee, S., Park, M.S., Shin, J. \& Kim, Y.W. (2018). Effect of the individual and combined use of cardanol-based plasticizers and epoxidized soybean oil on the properties of PVC. Polym. Degrad. Stabil. DOI: 10.1016/j.polymdegradstab.2017.11.002.

19. Chaudhary, B.I., Nguyen, B., Smith, P., Sunday, N. \& Luong, M. (2015). Bis(2-ethylhexyl) succinate in mixtures with epoxidized soybean oil as bio-based plasticizers for poly(vinylchloride). Polym. Eng. Sci. 55 (3), 634-640. DOI: 10.1002/pen.23934.

20. Jia, P., Zhang, M., Hu, L., Feng, G., Bo, C. \& Zhou, Y. (2015). Synthesis and application of environmental castor oil based polyol ester plasticizers for poly (vinyl chloride). ACS Sustain. Chem. Eng. 3, 2187-2193. DOI: 10.1021/acssuschemeng.5b00449.

21. Gamage, P.K. \& Farid, A.S. (2011). Migration of novel epoxidized neem oil as plasticizer from PVC: Experimental design approach. J. Appl. Polym. SCI. 121(2), 823-838. DOI: 10.1002/app.33554.

22. Yang, B., Bai Y. \& Cao, Y. (2010). Effects of inorganic nano-particles on plasticizers migration of flexible PVC. $J$. Appl. Polym. Sci. 115(4), 2178-2182. DOI: 10.1002/app.31310.
23. Lacerda, T., Carvalho, A.F. \& Gandini, A. (2014). Two alternative approaches to the Diels-Alder polymerization of tung oil. RSC $A d v$. 4(51), 26829-26837. DOI: 10.1039/c4ra03416c.

24. Huang, K., Liu, Z., Zhang, J., Li, S., Li, M., Xia, J. \& Zhou, Y. (2014) Epoxy monomers derived from tung oil fatty acids and its regulable thermosets cured in two synergistic ways. Biomacromolecules. 15(3), 837-843. DOI: 10.1021/bm4018929.

25. Yang, X., Li, S., Xia, J., Song, J., Huang, K. \& Li, M. (2015). Novel renewable resource-based UV-curable copolymers derived from myrcene and tung oil: Preparation, characterization and properties. Ind. Crop. Prod. 63, 17-25. DOI: 10.1016/j. indcrop.2014.10.024.

26. Meiorin, C., Aranguren, M.I. \& Mosiewicki, M.A. (2015). Polymeric networks based on tung oil: Reaction and modification with green oil monomers. Eur. Polym. J. 67, 551-560. DOI: 10.1016/j.eurpolymj.2015.01.005.

27. Jia, P., Hu, L., Yang, X., Zhang, M., Shang, Q. \& Zhou, Y. (2017). Internally plasticized PVC materials via covalent attachment of aminated tung oil methyl ester. RSC $A d v$. 7(48), 30101-30108. DOI: 10.1039/C7RA04386D.

28. Jia, P., Zhang, M., Hu, L., Song, F., Feng, G. \& Zhou, Y. (2017). A strategy for nonmigrating plasticized PVC modified with mannich base of waste cooking oil methyl ester. Sci Rep. 2018; 8: 1589. DOI: 10.1038/s41598-018-19958-y.

29. Yao, Q. \& Wilkie, C.A. (2001).Thermal degradation of PVC in the presence of polystyrene. J. Vinyl. Addit. Technol.7(1), 26-36. DOI: 10.1002/vnl.10261.

30. Soudais, Y., Moga, L., Blazek, J. \& Lemort, F. (2007). Coupled DTA-TGA-FT-IR investigation of pyrolytic decomposition of EVA, PVC and cellulose. J. Anal. Appl. Pyrolysis. 78(1):46-57. DOI: https://doi.org/10.1016/j.jaap.2006.04.005.

31. Li, Y., Wang, C., Wang G. \& Qu, Z. (2008). Application of the long-chain linear polyester in plastification of PVC. $J$. Wuhan Univ. Technol. 23(1), 100-104. DOI: 10.1007/S11595006-1100-3.

32. Yin, B. \& Hakkarainen, M. (2010). Oligomeric isosorbide esters as alternative renewable resource plasticizers for PVC. $J$. Appl. Polym. Sci. 119(4), 2400-2407. DOI: 10.1002/app.32913.

33. Gonzalez, N. \& Fernandez-Berridi, M.J. (2006). Application of fourier transform infrared spectroscopy in the study of interactions between PVC and plasticizers: PVC/plasticizer compatibility versus chemical structure of plasticizer. J. Appl. Polym. Sci. 101, 1731-1737. DOI: 10.1002/app.23381.

34. Suresh, S.S., Mohanty, S. \& Nayak, S.K. (2017). Bio-based epoxidised oil for compatibilization and value addition of poly (vinyl chloride) (PVC) and poly(methyl methacrylate) (PMMA) in recycled blend. J. Polym. Res. 24, 120. DOI: https://doi.org/10.1007/s10965-017-1282-8. 